\title{
Measurement of soluble proteins in lung secretions
}

In performing its role as a gas exchanging organ the human lung constantly exposes a large surface area to the atmosphere, which contains particulate and chemical material either environmental in origin or self administered. There are several surface defences, however, that protect the lung from these potentially toxic substances; these include phagocytic cells, mucus, ciliated epithelium, and proteins such as the immunoglobulins and proteinase inhibitors.

For most people this protective "screen" enables lung function and architecture to be preserved throughout life. A small proportion of the population, however, develop symptomatic and destructive, sometimes fatal, lung diseases. The events which result in failure of the normal protective mechanisms within the lung are largely unknown.

Although the "accessibility" exposes the lung to environmental hazards, it also offers the unique opportunity to study events where the exposure takes place, at the lung air interface. With the advent of fibreoptic bronchoscopy it became possible to obtain secretions and cells directly from the surface of the lung, where the defence systems are active. The application of modern research techniques in biochemistry, immunology, and cellular biology has enabled a closer study of the immediate environment of the lung to be made in both health and disease.

Potentially this form of research could provide new insight into the specific defects in the protective screen responsible for the susceptibility of individuals to the development of disease. It might become possible to identify those individuals in the population who are most at risk from lung disease and to provide information necessary for more rational and specific approaches to prevention and cure.

'Despite all this promise and the rapidly expanding literature on all aspects of pulmonary defence there remains uncertainty about the interpretation of results obtained from bronchoalveolar lavage specimens. This is particularly true of the study of proteins in lung secretions and is the consequence of many things, including lack of information concern-

Address for reprint requests: Dr RA Stockley, General Hospital, Birmingham B4 6NH. ing the role of the proteins and uncertainty about the accuracy of their measurement and the effect of dilution by fluid instilled to collect secretions as well as the uncertain effect of factors such as inflammation and the local production and local metabolism of proteins, which determine the concentration of proteins in the secretions. It therefore seems appropriate at this stage to review some of the protein studies that have been performed and the problems that are encountered in interpreting the results.

Soluble proteins were first identified in lung secretions by Warfringe, ' who in 1955 used paper electrophoresis to demonstrate the presence of several proteins in whole sputum. This work was confirmed in 1961 by Atassi et al, ${ }^{2}$ who identified from three to seven proteins in pathological sputum. The source of these proteins was uncertain but Brogan suggested that at least some of them were serum proteins. ${ }^{3}$ In later studies it was suggested that the quantity of protein present was dependent on either passive transudation or active transport from the serum into the secretion and furthermore that the concentration of serum proteins in sputum rises during inflammation. ${ }^{4}$ Further studies ${ }^{5}$ showed the presence of a variety of proteins that were not usually detectable in normal human serum, including lysozyme, lactoferrin, myeloperoxidase, secretory component, and amylase.

These early studies suggested at least three mechanisms which could account for the presence and concentration of proteins within the lung secretions: passive transudation from serum, active transport from serum to the secretions, and local production within the lung. Combinations of these mechanisms, it was realised, might occur. ${ }^{6}$ Direct evidence for any of these processes, however, is not abundant.

\section{Passive transudation}

The observation that radiolabelled albumin which has been injected into the peripheral circulation later appeared in lung secretions provided clear indication that transudation can occur.' Similarly, the finding that a rise in the concentration of $\alpha_{1}$ antitrypsin in lung secretions follows intravenous administration of the protein to $\alpha_{1}$ antitrypsin 
deficient subjects ${ }^{89}$ confirms that protein movement can take place from serum to the secretions.

Although the route of entry of proteins into the lung secretions is uncertain it has been suggested that a filtration system operates, which limits the concentration of the serum proteins according to their molecular size. ${ }^{10} \mathrm{~A}$ similar effect has been observed for other body fluids, such as cerebrospinal fluid $^{11}$ and amniotic fluid. ${ }^{12}$ The presence of a molecular filtration effect can be demonstrated by measuring the relative concentrations of proteins in the secretion and in corresponding serum samples in bronchitic patients. The secretion to serum concentration ratio is found to be inversely proportional to protein size. ${ }^{6}$

\section{Active transport}

At present it is uncertain whether there are mechanisms for the selective uptake of proteins either from serum or from the local environment of the lung and their active transport into the lung secretions. It has been suggested that the mechanism whereby dimeric IgA enters the secretion after binding to secretory component on the epithelial cells might include an active process transporting the protein across the cell. ${ }^{13}$ A similar mechanism has been demonstrated within the rat liver. ${ }^{14}$ Several related facts suggest that this also occurs in the human lung. Firstly, secretory component has been identified on lung epithelial cells. ${ }^{15}$ Secondly, evidence has been produced that submucosal lymphocytes manufacture IgA. ${ }^{16}$ Thirdly, the IgA found in secretions is bound to secretory component. Nevertheless, actual binding and transport of $\operatorname{IgA}$ in vivo in man has not yet been demonstrated.

\section{Local production}

Some proteins (such as secretory component) are only found in secretions and, although direct evidence of their manufacture by lung cells in vitro is lacking, it is difficult to explain their presence by any other mechanism. In the case of proteins which are also found in serum, evidence of local production is less certain. If the concentration of the protein in the secretion relative to that in serum is higher than can be explained by simple diffusion (after molecular size has been allowed for) it can be argued that a local mechanism exists for preferentially concentrating the protein. This mechanism could be active transport, a lower rate of local catabolism of the protein concerned than of other serum proteins, or local production; further evidence is required to prove the last of these. The necessary indirect evidence to support the theory of a local source of pro- duction can be provided by studies showing the presence of the proteins in lung cells immunohistochemically, production of the proteins by the cells in vitro, and a positive relationship between the high concentration of the protein and the cells implicated in its production (such as the relationship between IgG and lymphocytes ${ }_{7}^{17}$ ).

Although these general concepts of the mechanisms concerned in determining the concentration of proteins in lung secretions are relatively simple, there are many practical considerations that can affect the measurements and thus complicate the interpretation of results in both normal and pathological lungs.

\section{Mucus}

All samples of lung secretions, whether collected as expectorated sputum, by direct aspiration from the upper bronchial tree, or as bronchoalveolar secretions obtained by lavage techniques, contain some mucus. This makes the measurement of proteins by immunological techniques difficult, so that all secretions require special treatment before the measurements are made. In the past workers have made the secretions homogeneous either by chemical (enzyme degradation) or physical (ultrasonification) techniques. Since both techniques are likely either to damage the proteins or to rupture cells, thereby releasing further proteins, homogenisation of the secretions is probably the least satisfactory approach.

Most workers separate the mucus from the liquid phase by techniques that depend on the nature of the secretions studied. Ultracentrifugation is used for samples which are predominantly mucus (sputum and tracheobronchial secretions) and this separates them into a sol phase and a gel phase pellet. The former phase is studied and the gel phase discarded. Samples obtained by lavage techniques are usually strained through gauze to remove the larger amounts of mucus and then centrifuged at either low or high speed for lengths of time which may vary from 10 to 90 minutes. Despite these different techniques and centrifugation methods, however, broadly similar results are obtained..$^{18}$ It has to be accepted that whatever form of separation technique is used a proportion of some proteins, such as $\operatorname{IgA},{ }^{19}$ albumin, ${ }^{20}$ and leucocyte elastase, ${ }^{21}$ may bind to the mucus and thus be excluded from subsequent analysis. Despite this the soluble phase proteins behave in a manner suggestive of size dependent limitation of diffusion from serum, with "local production" of some specific proteins. ${ }^{6}$ The results suggest that the behaviour of most proteins can be assessed from the sol phase and furthermore that this phase does contain the diffusible protein. 
Whether or not an important proportion of protein that might reflect the pathogenesis of lung disease is permanently bound to lung mucus remains uncertain.

\section{Collection of samples}

Most lung secretions are, at best, a mixture derived from different parts of the lung. Any sample is likely to contain secretion derived from different anatomical regions of the lung as well as from normal and diseased areas. In this respect sputum is the least satisfactory secretion-firstly, because it is principally a mixture of material from the ciliated mucus secreting areas of the lung and thus it probably does not contain representative quantities of peripheral bronchial and alveolar secretions; and, secondly, because it is contaminated by saliva and nasopharyngeal secretions. The effect of this contamination is uncertain. Saliva contains very little serum derived protein and its principal effect is merely to dilute the overall concentration of these proteins in the lung secretion. Secretory $\operatorname{IgA}$ and amylase are, however, present in saliva in relatively higher concentrations than are serum proteins, so that contamination by saliva leads to less dilution of these proteins in the lung secretions. Provided that precautions are taken to minimise the problem of contamination, saliva should have little effect on the protein profile of the secretions obtained. Indeed, recent data suggest that the variability of $\operatorname{IgA}$ in sputum samples both within and between patients is similar to that of albumin despite the likelihood of salivary contamination. ${ }^{22}$ The dilutional effect of saliva is still, however, the major problem and this is conventionally overcome by the estimation of protein ratios within the secretion, ${ }^{6}$ although recent work suggests that the use of such ratios may not significantly alter the variability of the results obtained..$^{22}$ This suggests that at least some of the variability between protein concentration ratios in sputum is not simply due to the dilutional effect of saliva but may represent inherent variability of protein movements in the secretion itself. This point is further discussed below.

The obvious solution to the problem of saliva and nasopharyngeal contamination is to obtain samples directly from the bronchial tree. Unfortunately, the procedure itself can alter the nature of the secretions. Most studies are performed with the fibreoptic bronchoscope. The standard technique usually includes administration of atropine before the procedure, to reduce the volume of secretions, and the introduction of lignocaine directly into the bronchial tree as a local anaesthetic. Although these procedures may affect the physical properties of the secre- tions they do not seem to alter the results of sol phase protein measurements. Recent studies show that the relationships between proteins obtained from sputum before bronchoscopic procedures are similar to those obtained from samples collected during bronchoscopy. ${ }^{18}$ Thus the use of protein ratios appears to be a satisfactory means of overcoming the problems of variable dilution by saliva, lignocaine, and lavage fluid as well as the effect of reduction in volume due to atropine.

The nature of the secretions may be further altered by the physical effects of placing a fibreoptic bronchoscope within the bronchial tree. ${ }^{23}$ Even in the most experienced hands it is difficult to ensure that the mucosa sustains no minor trauma. Mucosal trauma might at best lead to some leakage of serum proteins and can cause contamination of the secretion by microscopic traces of blood. This is particularly a problem of bronchoalveolar lavage. During this procedure the bronchoscope is wedged into a subsegmental bronchus and aliquots of lavaging fluid are instilled and subsequently aspirated (usually gently to avoid further trauma). Samples containing erythrocytes can be discarded (though rarely is such information provided), but there is no way of identifying the effects of minor trauma on measurements. Contamination would tend to produce a protein profile that was more like that of serum. The similarity of results obtained for sputum, direct bronchial aspirate and bronchoalveolar lavage fluid ${ }^{18}$ suggests that, if such trauma occurs, the effect is probably minimal.

A further problem related to the collection of samples is that of variation of protein content with time. It has been shown recently ${ }^{22}$ that there is considerable variability not only in the actual secretion concentrations of the proteins measured but also in the amounts of protein that are derived from serum and "locally produced." This variability is found between patients in an apparently homogeneous group and also between samples from the same individual on consecutive days. The use of protein ratios (see below) enables the variability to be reduced only if the proteins being measured enter the secretions in a similar manner. ${ }^{22}$

\section{Quantification and qualitative assessment}

Individual proteins are quantified within lung secretions by various standard immunological techniques, including rocket immunoelectrophoresis, radial immunodiffusion, and enzyme linked immunosorbent assay (ELISA). The choice of technique depends on the size and concentration of the protein to be measured as well as on availability. All of the techniques, however, require the use of a specific 
antiserum to the protein being measured as well as a standard protein of known concentration for comparison. The accuracy of the techniques depends on physicochemical identity between the protein being measured and the standard protein used for comparison. ${ }^{24}$ This identity may not be assumed in lung secretions, where proteins such as $\alpha_{1}$ proteinase inhibitor and neutrophil elastase can interact together, resulting in physicochemical alterations and hence major errors in quantification. ${ }^{25}{ }^{26}$ Similar problems may occur in measurements of the cleavage products of $\mathrm{C} 3$ and $\mathrm{C5}$ within the lung. Immunoglobulin $A$ is also subject to major quantitative errors if the secretory form is compared with the monomeric (or serum) form, which may be used as a standard. ${ }^{27}$ Possibly careful selection and assessment of the technique used will overcome these problems. Indeed, secretory IgA can be measured more accurately, ${ }^{28}$ though such methods are not commonly used.

Error may be introduced if batches of antiserum, even those from the same commercial source, are not identical. In these circumstances widely different results may be obtained even for the same sample. ${ }^{25}$ Monoclonal antibodies may prove to be less variable than polyclonal antibodies provided that they are directed against an antigenic portion of the protein that is unlikely to change.

Some proteins, in particular $\alpha_{1}$ proteinase inhibitor, can also be subjected to qualitative assessment. Provided that the quantification of the protein is correct, much can be learnt about its role by assessing its ability (and that of other proteinase inhibitors) to inhibit enzymes. The validity of the results depends, however, on the purity and activity of the enzyme used. Commerical preparations of enzymes such as porcine pancreatic elastase (used to assess $\alpha_{1}$ proteinase inhibitor), though relatively pure, are often only $60-70 \%$ active (unpublished observation). The specific activity for each batch must, therefore, be established before the results can be interpretated. Even if this is taken into account daily variability in the inhibitory capacity of proteins such as $\alpha_{1}$ proteinase inhibitor still exists and must be considered in the analysis of short term studies. ${ }^{29}$

\section{Internal standardisation of results}

The major problem encountered when the results of protein estimation within the lung are being interpreted is the variability which results from dilution of the secretions, particularly dilution by lavage fluid as mentioned above, and this is worthy of further consideration. The difficulty has usually been overcome by a process of internal standardisation, in which protein concentrations are expressed as ratios in relation to the concentration of a standard substance present in secretions. The ideal standard would be a substance which remained present in the lung secretions in a constant concentration in both health and disease. Several internal standards have been used but all have some disadvantages which may affect the interpretation of the results.

1 The total protein content of the secretion has been used by several workers. ${ }^{30-32}$ Interpretation of differences between groups depends on the assumption that the total protein content is the same in each group. This is unlikely to be true since changes in the inflammatory cell component alone may have major effects on the type and amount of the total protein present. Indeed, until all the proteins being measured have been clearly identified, changes in one in relation to the total can have very little clear meaning.

2 The use of monomeric (7S) $\operatorname{IgA}$ as a standard $^{33}$ is based on the assumption that it is largely derived from serum. Recent work, however, has suggested that a proportion of $7 S \mathrm{IgA}$ is produced locally in the lung in patients with bronchitis. ${ }^{34}$ In view of this dual origin its concentration will depend both on pulmonary inflammation altering transudation from serum and on changes in local production both between individuals and between disease groups.

3 Special methods may be applicable in the case of secretory $\operatorname{IgA}$ (which is assumed to be assembled in the lung from two molecules of $\operatorname{IgA}$ linked together and associated with secretory component). The use of a marker substance which has diffused from serum, such as albumin, may be inappropriate as a standard for this locally produced protein. ${ }^{22}$ Measurement of several factors unique to the assembly of the secretory IgA molecule might, however, provide appropriate standardisation for its study. ${ }^{35}$

4 It has been suggested that potassium may be a useful standard..$^{36}$ Potassium ion does not, however, show a constant relationship to other components of bronchoalveolar lavage fluid when increasing volumes of lavage fluid are used..$^{37}$ For this reason different results would be obtained even in the same individual when different initial volumes of lavage fluid were instilled. This is of major importance since the volume of lavage fluid used in different centres may vary from 60 to $300 \mathrm{ml}$.

5 Albumin has become most widely accepted as the standard for other proteins in lung secretions. Furthermore, the use of albumin has also received considerable critical appraisal in recent years. Albumin enters the lung secretions freely from the serum. Its concentration in the secretions will be 
dependent on the serum concentration and the degree of inflammation in the lung affecting protein transudation. It is thus useful as a means of standardising other proteins that are derived from serum and are of roughly similar molecular size. The use of albumin as a standard reduces the variability encountered in the measurement of $\alpha_{1}$ proteinase inhibitor even though this is an acute phase protein which may show variation between patients in its serum and hence secretion concentration. The effect is illustrated in the top panel of table 1 . The concentration of both albumin and protein $\mathrm{X}$ (for example, $\alpha_{1}$ proteinase inhibitor) show variation that is greater in the case of protein $X$ because of its acute phase nature. Correction of $X$ for albumin reduces the variability strikingly and the two proteins are present in the same relationship in the secretion as they are in the serum. In practice, although some variability persists as a consequence of the inherent variability of the immunological techniques (between batch variability $\approx 4 \%$ ), the use of albumin as an internal standard appears to be sound. ${ }^{22}$

Dilution of the secretion by bronchoalveolar lavage fluid might be expected to increase variability of the individual protein measurements (lower panel, table 1). This can, however, be eliminated by standardisation for albumin concentration and comparison with serum concentration can eliminate the disturbance caused by dilution and give results similar to those for the undiluted secretions (top panel, table 1).

\section{Local production}

In the case of proteins which are locally produced or Table 1 Idealised results (obtained from references 6,18 , 22,40 , and 42) for secretion albumin (Alb) and a protein $(X)$ which is of the same molecular size entering the secretions by diffusion from serum: means and standard deviations, with the relevant between subject coefficients of variation $(C V)$, for four secretions. The top panel indicates the results from a secretion in its native state and the lower panel the results for a secretion obtained by bronchoalveolar lavage

\begin{tabular}{|c|c|c|c|c|}
\hline & $A l b$ & $X$ & $X / A l b$ & $\begin{array}{l}\text { Compared } \\
\text { with serum }\end{array}$ \\
\hline$\underset{\text { CV\% }}{\operatorname{Mean}(\mathrm{SD})}$ & $\begin{array}{l}15 \cdot 0 \\
20 \cdot 0 \\
25 \cdot 0 \\
30 \cdot 0 \\
22 \cdot 5(6 \cdot 45) \\
28 \cdot 7\end{array}$ & $\begin{array}{l}10 \cdot 0 \\
19 \cdot 0 \\
15 \cdot 0 \\
28 \cdot 0 \\
18 \cdot 0(7 \cdot 62) \\
42 \cdot 3\end{array}$ & $\begin{array}{l}0.67 \\
0.95 \\
0.60 \\
0.93 \\
0.79(0.18) \\
22 \cdot 8\end{array}$ & $\begin{array}{l}1.0 \\
1.0 \\
1.0 \\
1.0 \\
1.0 \\
0\end{array}$ \\
\hline $\begin{array}{l}\text { Acute phase } \\
\text { diluted } \\
\text { Mean (SD) } \\
\text { CV\% }\end{array}$ & $\begin{array}{l}1.5 \\
0.4 \\
5 \cdot 0 \\
6 \cdot 0 \\
3 \cdot 23(2 \cdot 70) \\
83.6\end{array}$ & $\begin{array}{l}1 \cdot 0 \\
0 \cdot 38 \\
3 \cdot 0 \\
5 \cdot 6 \\
2 \cdot 50(2 \cdot 35) \\
94 \cdot 0\end{array}$ & $\begin{array}{l}0.67 \\
0.95 \\
0.60 \\
0.93 \\
0.79(0.18) \\
22.8\end{array}$ & $\begin{array}{l}1.0 \\
1.0 \\
1.0 \\
1.0 \\
1.0 \\
0\end{array}$ \\
\hline
\end{tabular}

Table 2 Idealised results (obtained from references 6,18 , 22, 40, and 42) for albumin (Alb) and a "locally produced" protein $(Y)$ that also has a serum derived component (for example, IgA): means and standard deviations, with the relevant between subject coefficients of variation (CV), for four secretions. The top panel gives the results for the native secretion. The middle panel shows that increased transudation of albumin and $Y$ from the serum during inflammation reduces the difference between albumin and $Y$ even though the locally produced component remains unaltered. The lower panel shows the results that could be obtained if the secretion in the top panel were obtained by bronchoalveolar lavage

\begin{tabular}{|c|c|c|c|c|}
\hline & $A l b$ & $Y$ & $Y / A l b$ & $\begin{array}{l}\text { Compared } \\
\text { with serum }\end{array}$ \\
\hline $\begin{array}{l}\text { Local } \\
\text { production }\end{array}$ & $\begin{array}{l}5 \cdot 0 \\
6 \cdot 5 \\
6 \cdot 0 \\
5 \cdot 5 \\
5 \cdot 75(0.65) \\
11.3\end{array}$ & $\begin{array}{l}10 \cdot 0 \\
9 \cdot 0 \\
11 \cdot 0 \\
14 \cdot 0 \\
11 \cdot 0(2 \cdot 16) \\
19 \cdot 6\end{array}$ & $\begin{array}{l}2 \cdot 0 \\
1 \cdot 38 \\
1 \cdot 83 \\
2 \cdot 55 \\
1 \cdot 94(0.48) \\
24 \cdot 7\end{array}$ & $\begin{array}{c}8 \cdot 0 \\
6 \cdot 3 \\
7 \cdot 4 \\
9 \cdot 1 \\
7 \cdot 7(0 \cdot 48) \\
15 \cdot 2\end{array}$ \\
\hline $\begin{array}{l}\text { Mean (SD) } \\
\text { CV\% }\end{array}$ & $\begin{array}{l}15 \cdot 0 \\
20 \cdot 0 \\
25 \cdot 0 \\
30 \cdot 0 \\
22 \cdot 5(6 \cdot 5) \\
28.7\end{array}$ & $\begin{array}{l}16 \cdot 0 \\
17 \cdot 0 \\
21 \cdot 0 \\
26 \cdot 0 \\
20(4 \cdot 54) \\
22 \cdot 7\end{array}$ & $\begin{array}{l}1.07 \\
0.85 \\
0.84 \\
0.87 \\
0.91(0.11) \\
12.1\end{array}$ & $\begin{array}{l}2 \cdot 0 \\
1 \cdot 6 \\
2 \cdot 4 \\
2 \cdot 7 \\
2 \cdot 18(0.48) \\
22 \cdot 0\end{array}$ \\
\hline $\begin{array}{l}\text { Mean (SD) } \\
\text { CV\% }\end{array}$ & $\begin{array}{l}0.1 \\
0.065 \\
0.12 \\
1.1 \\
0.35(0.50) \\
142.8\end{array}$ & $\begin{array}{l}0.2 \\
0.09 \\
0.20 \\
2.8 \\
0.82(1 \cdot 32) \\
160.9\end{array}$ & $\begin{array}{l}2 \cdot 0 \\
1 \cdot 38 \\
1.83 \\
2 \cdot 55 \\
1.94(0 \cdot 48) \\
24 \cdot 7\end{array}$ & $\begin{array}{r}8 \cdot 0 \\
6 \cdot 3 \\
7 \cdot 4 \\
9 \cdot 1 \\
7 \cdot 7(0 \cdot 48) \\
15 \cdot 2\end{array}$ \\
\hline
\end{tabular}

which enter the lung secretions by an active transport mechanism, attempts to reduce the variability due to sampling difficulties by using standardisation for albumin content may result instead in an increase in variability. This is illustrated in table 2 . The top panel shows theoretical values for variability of both albumin and a locally produced protein $\mathrm{Y}$ (such as secretory $\operatorname{IgA}$ ); the proteins enter the secretions by independent mechanisms, and the variability is increased when $\mathrm{Y}$ is standardised for albumin (this has recently been shown in vivo for $\operatorname{IgA}{ }^{22}$ ). Furthermore, since $\mathrm{Y}$ is largely produced locally the ratio of $Y$ to albumin in the secretions is greater than in the corresponding serum and this provides a measure of the proportion of $\mathrm{Y}$ that is produced locally. If $\mathrm{Y}$ is the same size as albumin the ratio of the serum derived proportion of $Y$ to albumin would be the same in the secretions as in the serum. In these circumstances the results in table 2 would suggest that there is 7.7 times as much $\mathrm{Y}$ in the secretions than could be accounted for by diffusion from serum (that is, the major component, about $88 \%$, is locally produced). In practice, the situation (particularly for $\operatorname{IgA}$ ) is rendered more complicated by differences in molecular size. ${ }^{6}$ If the size of the protein 
is large enough to restrict its movement into the secretions by diffusion from serum (IgG, IgM, $\alpha_{2}$ macroglobulin) then even protein to albumin ratios in secretions that are similar to or lower than the corresponding serum value can indicate the presence of an important local mechanism to concentrate the protein. ${ }^{638}$

At best, when a protein to albumin ratio in secretions is greater than would be predicted on the assumption of diffusion from serum, the evidence suggests a local mechanism that has increased the concentration of the protein in the lung. Further evidence such as immunohistochemical demonstration of the protein in lung cells and in vitro production of the protein by those cells is necessary to establish that local production occurs.

Inflammation of the lung results in increased protein transudation from serum into the lung. The concentration of lung albumin will rise in these circumstances and there will be a change in the relationship between albumin and the local protein. The concentration ratio of $\mathrm{Y}$ to albumin (middle panel, table 2) is lower than in the non-inflamed state and the difference between lung and serum is less pronounced $(2.18$ times as high compared with $7 \cdot 7$ in the non-inflamed lung). Changes of this sort have led some authors to suggest a failure of local production of IgA during acute exacerbation of chronic bronchitis ${ }^{39}$ though the artefact has been recently recognised both in the measurement of $\operatorname{IgA}{ }^{40}$ and in the interpretation of lung fibronectin concentrations, ${ }^{41}$ where local protein production may actually increase during the inflamed state despite a fall or lack of change in its relationship to albumin.

Standardisation for albumin must be eyed with even greater caution when local proteins are studied in bronchoalveolar lavage fluid. The variable dilution of secretions by the lavage fluid will increase the variability of the concentrations of all the proteins recovered (lower panel, table 2 ). In the example, however, when the concentration of protein $\mathrm{Y}$ in the fluid is standardised for albumin and the concentration ratio of $\mathrm{Y}$ to albumin compared with that in serum, the variability will be the same as in the undiluted secretion (top panel, table 2) and could show significant reduction even if the standardisation procedure is not really appropriate for the protein being studied. Recent work assessing the secretory IgA system in lung secretions offers some support for this. ${ }^{42}$ IgA results show increased variability when albumin is used as a standard in sputum measurements but decreased variability when it is used for bronchoalveolar lavage fluid in the same subjects despite the similarity of the relationship of the components of the secretory $\operatorname{IgA}$ system in the two secretions. Clearly, better methods are required for assessing proteins produced locally in the bronchial tree. Possibly better internal standards can be found. For example, study of the individual components of the secretory $\operatorname{IgA}$ molecule together might clarify and identify changes in $\operatorname{IgA}$ production within the bronchial tree. An alternative approach would be to use the absolute concentrations of the protein in each secretion alone (as for serum proteins). This, however, will require the development of methods which could accurately determine the dilution of the secretion by lavaging fluid. These may require the introduction of large molecular markers or radiolabels into the lavaging fluid. Such a method, using a methylene blue marker, has been reported recently. ${ }^{43}$ With improved techniques changes in the release, production, and metabolism of local proteins as well as changes in protein transudation from serum might be identified with more certainty. This would allow more detailed study of the relationship between the protein content of secretions and disease processes in the lung.

Ever since the first identification of proteins in sputum their study in lung secretions has seemed to hold the promise of improved understanding of lung diseases. Already vital clues have been provided in diseases such as emphysema, fibrosing alveolitis, and the adult respiratory distress syndrome. Further progress, however, will probably be limited until better methods of collection, analysis, and correction of results and, moreover, better standardisation of the techniques between laboratories have be achieved.

I would like to thank Dr D Burnett for advice on the manuscript and Miss J Downs for her typing.

\section{RA STOCKLEY General Hospital Birmingham}

\section{References}

1 Warfringe LE. Paper electrophoresis of sputum in bronchiolar carcinoma. Acta Med Scand 1955;153:49-52.

${ }^{2}$ Atassi MZ, Barker SA, Houghton LE, Mullard KS. Mucoproteins of bronchial mucus. Nature 1961; 192: $1269-70$.

${ }^{3}$ Brogan TD. The high molecular weight components of sputum. Br J Exp Pathol 1960;41:288-97.

${ }^{4}$ Ryley HC, Brogan TD. Variation in the composition of sputum in chronic chest diseases. Br J Exp Pathol 1968;49:625-33.

${ }^{5}$ Ryley HC. An immunoelectrophoretic study of the soluble secretory proteins of sputum. Biochim Biophys Acta 1972;271:300-9.

- Stockley RA, Mistry M, Bradwell AR, Burnett D. A study of plasma proteins in the sol phase of sputum from patients with chronic bronchitis. Thorax 1979;34:777-82. 
${ }^{7}$ Bonoma L, D' Addabbo A. $\left[\mathrm{I}^{131}\right]$ albumin turnover and loss of protein into the sputum in chronic bronchitis. Clin Chim Acta 1964;10:214-22.

${ }^{8}$ Makino S, Reed CE. Distribution and elimination of exogenous alpha ${ }_{1}$ antitrypsin. J Lab Clin Med 1970;75:742-6.

${ }^{9}$ Gadek JE, Klein HG, Holland PV, Crystal RG. Replacement therapy of alpha 1-antitrypsin deficiency. Reversal of the protease-antiprotease imbalance within the alveolar structures of PiZ subjects. $J$ Clin Invest 1981;68:1158-65.

${ }^{10}$ Boyd RDH, Hill JR, Humphreys PW, Normand ICS, Reynolds EOR, Strang LB. Permeability of lung capillaries to macromolecules in foetal and newborn lambs and sheep. J Physiol 1969;201:567-88.

"Felgenhaur K. Protein filtration and secretion at human body fluid barriers. Pftügers Arch 1980;384:9-17.

${ }^{12}$ Burnett D, Bradwell AR. The origin of plasma proteins in human amniotic fluid: the significance of alpha antichymotrypsin complexes. Biol Neonate 1980; 37:302-7.

${ }^{13}$ Tomasi TB. Secretory immunoglobulins. $N$ Engl J Med 1972;287:500-6.

${ }^{14}$ Hall JG, Gyure LA, Payne AWR. Comparative aspects of the transport of immunoglobulin A from blood to bile. Immunology 1980;41:899-902.

${ }^{15}$ Goodman MR, Link DW, Brown WR, Nakane PK. Ultrastructural evidence of transport of secretory IgA across bronchial epithelium. Am Rev Respir Dis 1981;123: 115-9.

${ }^{16}$ Lamm ME. Cellular aspects of immunoglobulin A. Adv Immunol 1976;22:223-90.

${ }^{17}$ Rankin JA, Naegel GP, Schrader CE, Matthay RA, Reynolds HY. Air space immunoglobulin production and levels in broncho-alveolar lavage fluid of normal subjects and patients with sarcoidosis. Am Rev Respir Dis 1983;127:442-8.

${ }^{18}$ Wiggins J, Hill SL, Stockley RA. Lung secretion solphase proteins: comparison of sputum with secretions obtained by direct sampling. Thorax 1983;38:102-7.

${ }^{19}$ Bhaskar KR, O'Sullivan DDO, Lopez-Vidriero MT, Reid LM. Characterisation of sol and gel phases of infected and mucoid sputum samples from a chronic bronchitic patient. Adv Exp Med Biol 1982; 144:361-4.

${ }^{20}$ Roberts GP. The role of disulphide bonds in maintaining the gel structure of bronchial mucus. Arch Biochem Biophys 1976;173:528-37.

21 Ohlsson K, Tegner H. Granulocyte collagenase, elastase and plasma protease inhibitors in purulent sputum. Eur J Clin Invest 1975;5:221-7.

22 Wiggins J, Stockley RA. Variability in sputum sol phase proteins in chronic obstructive bronchitis. The value of using albumin for standardization. Am Rev Respir Dis 1983;128:60-4.

${ }^{23}$ Reifenrath R, Zimmermann I. Blood plasma contamination of the lung alveolar surfactant obtained by various sampling techniques. Respir Physiol 1973; 18: $238-48$.

${ }^{24}$ Weeke B. Rocket immunoelectrophoresis. Scand J Immunol 1973;2,suppl:37-46.

${ }^{25}$ Stockley RA, Afford SC. The immunological assessment of $\alpha_{1}$ antitrypsin with reference to its function in bronchial secretions. Clin Sci 1983;65:373-81.

${ }^{26}$ Afford SC, Stockley RA. The effect of complexing and proteolysis on the immunological assessment of alpha antitrypsin and leucocyte elastase. Clin Sci 1982;63:32p (abstract).

${ }^{27}$ Delacroix DL, Dehennin JP, Vaerman JP. Influence of molecular size of $\operatorname{IgA}$ on its immunoassay by various techniques. II Solid-phase radioimmunoassays. $J$ Immunol Methods 1982;48:327-37.

${ }^{28}$ Sack DA, Neogi PKB, Khorshed AMD. Immunobead enzyme-linked immunosorbent assay for quantitating immunoglobulin $\mathbf{A}$ in human secretions and serum. Inf Immun 1980;29:281-3.

${ }^{29}$ Morrison HM, Afford SC, Stockley RA. Inhibitory capacity of alpha antitrypsin in lung secretions: variability and the effect of drugs. Thorax (in press).

${ }^{30}$ Warr GA, Martin RR, Sharp PM, Rosen R. Normal human bronchial immunoglobulins and proteins: effects of cigarette smoking. Am Rev Respir Dis 1977;116:25-30.

${ }^{31}$ Fick RB, Gee JBL, Reynolds HY. Lung lavage findings in chronic obstructive lung disease with recurrent Pseudomonas infections. Am Rev Respir Dis 1983; 127:65.

${ }^{32}$ Merrill WW, Goodman M, Matthay RA, Naegel GP, Vandevoorde JP, Myl AD, Reynolds HY. Carcinoembryonic antigen in the lung lining fluids of smoker and non smokers. Am Rev Respir Dis 1981;123:29-31.

${ }^{33}$ Hayem A, Scharfman A, Laine A, Lafitte JJ, Sablonnière B. Proteases and antiproteases in bronchoalveolar lavage. Bull Europ Physiopathol Respir 1980;16,suppl:247-60.

${ }^{34}$ Stockley RA, Afford SC, Burnett D. Assessment of $7 S$ and $11 S$ immunoglobulin A in sputum. Am Rev Respir Dis 1980;122:959-64.

${ }^{35}$ Stockley RA, Burnett D, Afford SC. The immunological measurement of "free" secretory piece and its relationship to local IgA production. Clin Exp Immunol 1981;45:124-30.

${ }^{36}$ Low RB, Davis GS, Giancola MS. Biochemical analyses of bronchoalveolar lavage fluids of healthy human volunteer smokers and non-smokers. Am Rev Respir Dis 1978;118:863-75.

${ }^{37}$ Davis GS, Giancola MS, Costanza MC, Low RB. Analyses of sequential bronchoalveolar lavage samples from healthy human volunteers. Am Rev Respir Dis 1982;126:611-6.

${ }^{38}$ Burnett D, Stockley RA. Serum and sputum $\alpha_{2}$ macroglobulin in patients with chronic obstructive airways disease. Thorax 1981;36:512-6.

${ }^{39}$ Soutar CA. Distribution of plasma cells and other cells containing immunoglobulin in the respiratory tract in chronic bronchitis. Thorax 1977;32:387-96.

${ }^{40}$ Stockley RA, Burnett D. Local IgA production in patients with chronic bronchitis: effect of acute respiratory infection. Thorax 1980;35:202-6.

${ }^{41}$ Rennard SI, Crystal RG. Fibronectin in human bronchopulmonary lavage fluid. Elevation in patients with interstitial lung disease. J Clin Invest 1981;69:113-22.

42 Wiggins J, Hill SL, Stockley RA. The secretory IgA system of the lung secretions in chronic obstructive bronchitis: comparison of sputum results with secretions obtained during fibreoptic bronchoscopy. Thorax (in press).

${ }^{43}$ Baughman RP, Bosken CH, Louden RG, Hurtubise P, Wessler T. Quantitation of bronchoalveolar lavage with methylene blue. Am Rev Respir Dis 1983;128: $266-70$. 